\title{
The Influence of Ultrasonic Frequency on the Properties of Ni-Co Coatings Prepared by Ultrasound-assisted Electrodeposition
}

\author{
Minqi SHENG ${ }^{1,2) \dagger}$, Chenkai $L V^{1)}$, Lan $H O N G^{1)}$, Mingwang $S H A O^{2)}$, \\ Kang $W A N^{1)}$ and Fan $L V^{1)}$ \\ 1) School of Iron and Steel, Soochow University, Suzhou 215021, China \\ 2) Institute of Functional Nano \& Soft Materials (FUNSOM), Soochow University, Suzhou 215123, China \\ [Manuscript received 24 March 2013, in revised form 5 September 2013] \\ (C) The Chinese Society for Metals and Springer-Verlag Berlin Heidelberg
}

\begin{abstract}
In this paper, $\mathrm{Ni}$-Co coatings were electrodeposited onto carbon steel substrates with the aid of ultrasonic agitation. The coatings were analyzed by energy dispersive X-ray analysis (EDX), X-ray diffraction analysis (XRD) and scanning electron microscopy (SEM). The effects of the ultrasonic frequency on the roughness, hardness and corrosion resistance of the $\mathrm{Ni}$-Co coatings were also investigated. The results indicated that the increase of the ultrasonic frequency from 20 to $120 \mathrm{kHz}$ reduced the $\mathrm{Ni}$ content and the grain size of $\mathrm{Ni}-\mathrm{Co}$ coatings. Moreover, the phase structure of the electrodeposited coatings was influenced by the ultrasonic frequency. Under $55 \mathrm{kHz}$ ultrasonic agitation, the $\mathrm{Ni}$-Co coating was single fcc phase and showed the finest roughness and the strongest corrosion resistance in $5 \mathrm{wt} . \% \mathrm{NaCl}$ solution at the ambient temperature. Under ultrasonic agitation with frequency of $90 \mathrm{kHz}$, the coating was a mixture of fcc and hcp structure and showed the maximal hardness of about $420 \mathrm{HV}$. Therefore, ultrasonic agitation helped decrease the roughness, and enhance hardness and corrosion resistance of $\mathrm{Ni}-\mathrm{Co}$ coatings.
\end{abstract}

KEY WORDS: Ni-Co alloys; Coatings; Electrodeposition; Ultrasound; Hardness; Corrosion

\section{Introduction}

Ni-Co alloy coatings have attracted widely attention due to its hardness and corrosion resistance as a replacement for hard chromium coating ${ }^{[1-4]}$. As the properties of Ni-Co coatings are seriously affected by their composition and structure, a reliable control of the composition and structure was an important issue for their wide applications. Many researchers investigated extensively the preparation of $\mathrm{Ni}-\mathrm{Co}$ coating by direct current electrodeposition ${ }^{[5]}$, pulse current electrodeposition ${ }^{[6]}$ or pulse reverse current electrodeposition ${ }^{[7]}$. The composition and structure of Ni-Co coatings could be controlled by changing the electrodeposition parameters, such as overvoltage, current density, pulse parameters in pulsed

† Corresponding author. Ph.D.; Tel.: +86 18251186252; Fax: +86 512 67160032; E-mail address: smqtg@hotmail.com (Minqi SHENG)

DOI: $10.1007 / \mathrm{s} 40195-013-0162-4$ electrodeposition $^{[6-10]}$. Yet, more investigation was needed to obtain Ni-Co coatings with higher hardness and anti-corrosion.

In recent years, ultrasound-assisted electrodeposition applied to deposit various metals (or alloys) and composite coatings due to the advantages, such as increasing the deposition rate, decreasing the internal stress of the deposited coatings, and reducing additives in the plating bath ${ }^{[1-15]}$. Although there were many works on ultrasound-assisted electrodeposition ${ }^{[11-20]}$, there was no report about the influence of ultrasonic frequency on the composition, structure and properties of Ni-Co coatings up to now.

In this study, the ultrasound-assisted electrodeposition was employed to deposit Ni-Co coatings. The influences of ultrasonic frequency on the composition, structure, roughness, hardness and corrosion resistance of the $\mathrm{Ni}-\mathrm{Co}$ coatings were investigated. The results showed that the ultrasonic frequency $(0$ $120 \mathrm{kHz}$ ) had significant impact on the characteristics 
and properties of the obtained Ni-Co coatings.

\section{Experimental}

Carbon steel plates were used as substrates. The exposed area of these pretreated carbon steel substrates was equal to $1 \mathrm{~cm}^{2}$ while the other surface areas were sealed with epoxy resin before the deposition. The electrodeposition was carried out in a conventional three-electrode cell connected with a Princeton VersaSTAT4 electrochemistry workstation. A platinum plate with an area of $2 \mathrm{~cm}^{2}$ was used as the anode, and a saturated calomel electrode (SCE) was used as the reference electrode. Ultrasonic agitation was performed in an ultrasound-assisted electrodeposition setup with the output power of $100 \mathrm{~W}$. The temperature of the water bath was controlled by a temperature controller. The detailed bath composition and experimental parameters are listed in Table 1 and 2 .

Table 1 Bath compositions for Ni-Co alloy coatings deposition

\begin{tabular}{cc}
\hline Bath composition & Concentration $(\mathrm{g} / \mathrm{L})$ \\
\hline $\mathrm{NiSO}_{4} \cdot 6 \mathrm{H}_{2} \mathrm{O}$ & 110.0 \\
$\mathrm{NiCl}_{2} \cdot 6 \mathrm{H}_{2} \mathrm{O}$ & 6.0 \\
$\mathrm{CoSO}_{4} \cdot 6 \mathrm{H}_{2} \mathrm{O}$ & 55.0 \\
$\mathrm{H}_{3} \mathrm{BO}_{3}$ & 12.5 \\
$\mathrm{C}_{6} \mathrm{H}_{8} \mathrm{O}_{9}$ & 5.6 \\
\hline
\end{tabular}

Table 2 Experimental parameters for Ni-Co alloy coatings deposition

\begin{tabular}{cc}
\hline Parameter & Value \\
\hline pH value & 4.0 \\
Temperature, $T$ & $40{ }^{\circ} \mathrm{C}$ \\
Current density, $j$ & $80 \mathrm{~mA} \cdot \mathrm{cm}^{-2}$ \\
Time, $t$ & $15 \mathrm{~min}$ \\
Ultrasonic frequency, $f$ & $0,20,55,90$ and $120 \mathrm{kHz}$ \\
\hline
\end{tabular}

The phase structure, composition, and morphology of as-deposited coatings were investigated by Xray diffraction spectrometer $(\mathrm{D} / \max -2200 \mathrm{~V})$ with a $\mathrm{Cu} K_{\alpha}$ radiation, energy dispersive $\mathrm{X}$-ray spectrometer (Oxford Instruments) and scanning electron microscopy (JEOL JSM-6700F).

The roughness of Ni-Co coatings was measured for 10 spots on each sample by a roughness meter (TR200). The Vickers hardness of Ni-Co coatings was measured using a microhardness tester (HXD-1000B) by loading a force of $0.245 \mathrm{~N}$ for $15 \mathrm{~s}$, and the average of 10 hardness measurement results was taken as the hardness value. In order to investigate the corrosion resistance of $\mathrm{Ni}-\mathrm{Co}$ coatings, the electrochemical behavior of the samples was analyzed by polarization plots and electrochemical impedance spectroscopy, using a Princeton VersaSTAT4 electrochemistry workstation. Polarization measurements were performed in 5 wt. $\% \mathrm{NaCl}$ solution at the ambient temperature with a potential scan rate of $1 \mathrm{mV} \cdot \mathrm{s}^{-1}$. Electrochemi- cal impedance spectroscopy tests were carried out potentiostatically at corrosion potential $\left(E_{\text {corr }}\right)$, with the voltage perturbation amplitude of $10 \mathrm{mV}$ in the frequency range from $10 \mathrm{kHz}$ to $0.01 \mathrm{~Hz}$.

\section{Results and Discussion}

\subsection{Composition of $\mathrm{Ni}$-Co coatings}

Fig. 1 shows the EDX measured Ni contents of the Ni-Co coatings deposited under different frequencies ultrasonic. It is clearly observed that the $\mathrm{Ni}$ content in the coatings deposited under ultrasonic agitation is higher than that under silent condition $(0 \mathrm{kHz})$, and the $\mathrm{Ni}$ content decreases with the ultrasonic frequencies increase from $20 \mathrm{kHz}$ to $120 \mathrm{kHz}$.

During Ni-Co co-deposition process, the $\mathrm{pH}$ value at the cathode surface is found to rise due to $\mathrm{H}^{+}$ ions consumption near the electrode and resulting in hydroxide ions increase ${ }^{[21-23]}$. The local increase of $\mathrm{pH}$ results in the formation of hydroxide precipitate of the low electrode potential metal Co and $\mathrm{CoOH}^{+}$, followed by its adsorption onto the cathode surface $^{[21-24]}$. This can be expressed as follows:

$$
\begin{gathered}
2 \mathrm{H}^{+}+2 \mathrm{e}^{-} \rightarrow \mathrm{H}_{2} \\
2 \mathrm{H}_{2} \mathrm{O}+2 \mathrm{e}^{-} \rightarrow \mathrm{H}_{2}+2 \mathrm{OH}^{-} \\
\mathrm{Co}^{2+}+\mathrm{OH}^{-} \rightarrow \mathrm{CoOH}^{+} \\
\mathrm{CoOH}^{+} \rightarrow \mathrm{Co}(\mathrm{OH})_{\text {ads }}^{+}
\end{gathered}
$$

The adsorbed cobalt hydroxide $\left(\mathrm{Co}(\mathrm{OH})_{\text {ads }}^{+}\right)$occupies the reaction sites, so that the deposition of the $\mathrm{Ni}$ which has high electrode potential metal is suppressed $^{[21,24]}$. When applying ultrasonic agitation, the asymmetrical collapse of cavitation bubbles originated from the ultrasonic cavitation induces the formation of high velocity jets of liquid toward the cathode surface ${ }^{[18]}$. As a result, the desorption of $\mathrm{Co}(\mathrm{OH})_{\text {ads }}^{+}$on the cathode surface is enhanced by the liquid jets, and consequently more reaction sites are available for $\mathrm{Ni}$ deposition to enrich the $\mathrm{Ni}-\mathrm{Co}$ coating with Ni.

It should be pointed out that with the increase in the ultrasonic frequency, the intensity of high velocity jets decreases since the ultrasonic cavitation decays $^{[19]}$. Therefore, less $\mathrm{Co}(\mathrm{OH})_{\text {ads }}^{+}$is desorbed and there are fewer reaction sites for $\mathrm{Ni}$ deposition on the cathode surface when the ultrasonic frequency is high, leading to the low $\mathrm{Ni}$ content in $\mathrm{Ni}-\mathrm{Co}$ coatings (shown in Fig. 1). These analyses confirm that the variation of the ultrasonic frequency can influence the electrodeposition process of Ni-Co coating. 


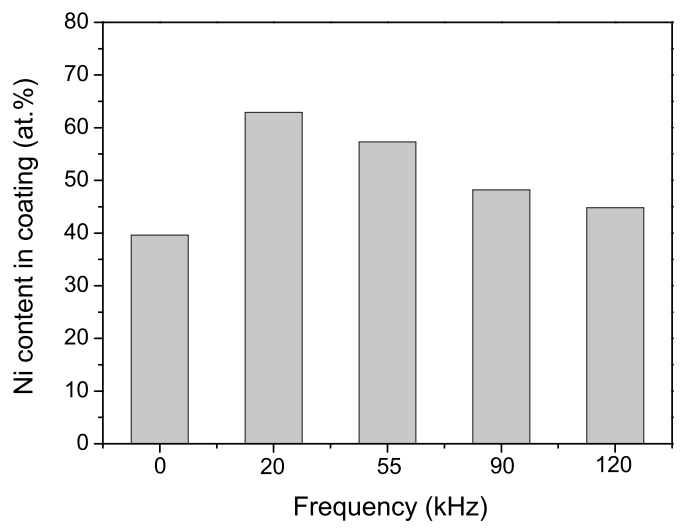

Fig. 1 The Ni contents of the Ni-Co coatings deposited under different frequencies ultrasonic

\subsection{Phase structure and morphology of Ni-Co coat- ings}

Fig. 2 shows the XRD patterns of the as-deposited coatings. The absence of Fe diffraction peak indicates that the carbon steel substrates are completely covered by the coatings. In XRD patterns, the fcc ( $\alpha$ $\mathrm{Ni})$ contributes to (111), (200) and (220) planes while the hcp ( $\varepsilon-\mathrm{Co})$ contributes to (100), (002), (101) and (110) planes. Under 20 and $55 \mathrm{kHz}$ ultrasonic agitation, no other diffraction peak is found except those peaks of fcc phase with a slight shift compared with those of pure Ni (JCPDS file No.04-0850). It is mainly because the Co atoms are incorporated into the crystalline lattice of $\mathrm{Ni}$. Under other deposition conditions, the diffraction peaks of hcp phase reveal the formation of a mixed crystal structure. Tury et al. ${ }^{[25]}$ pointed out that in this mixed crystal structure either a hexagonal Co cluster containing cubic structured $\mathrm{Ni}$ or a hexagonal Co cluster was built in the cubic structured Ni.

The grain size of Ni-Co coatings is determined using the Scherrer expression from XRD line broadening, as listed in Table 3. It is clearly showed that the introduction of ultrasonic agitation into the electrodeposition can refine the grain size. This is caused mainly by the following two reasons: (1) the high pressure acoustic steaming can interrupt the growth of grains; (2) the number of crystal nuclei on the cathode surface is increased under ultrasonic irradiation, because the instant local super cooling effect (caused by ultrasonic cavitation) decreases the radius of nucleation and leads to the increase of the nucleation rate.

From Table 3, it can also be observed that the

Table 3 The grain sizes of Ni-Co coatings deposited under different frequencies ultrasonic

\begin{tabular}{ccccc}
\hline $0 \mathrm{kHz}$ & $20 \mathrm{kHz}$ & $55 \mathrm{kHz}$ & $90 \mathrm{kHz}$ & $120 \mathrm{kHz}$ \\
\hline $61.6 \mathrm{~nm}$ & $39.3 \mathrm{~nm}$ & $31.7 \mathrm{~nm}$ & $25.2 \mathrm{~nm}$ & $14.5 \mathrm{~nm}$ \\
\hline
\end{tabular}

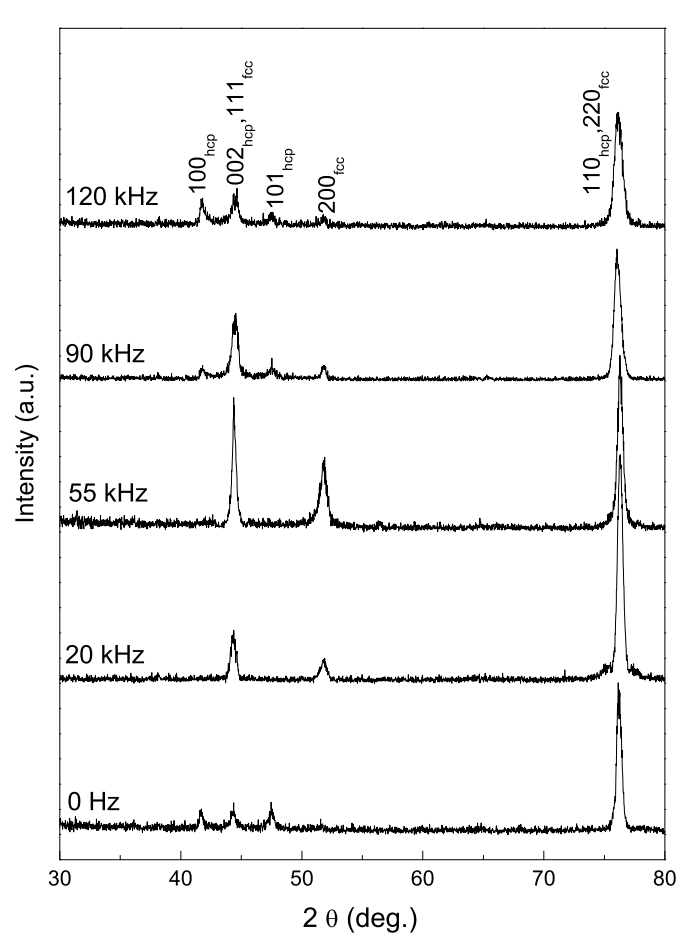

Fig. 2 XRD patterns of the Ni-Co coatings deposited under different frequencies ultrasonic

grain size of the coatings decreases with the ultrasonic frequency in the range of $20 \mathrm{kHz}$ to $120 \mathrm{kHz}$. The work of Coury et al. ${ }^{[26,27]}$ and Compton et al. ${ }^{[28]}$ have shown that the decrease in the intensity of ultrasonic cavitation leads to the increase in the thickness of diffusion layer, which finally gives an increasement in overpotential. It has been proved that a higher overpotential would boosts the nucleation rates and results in smaller nucleus radius ${ }^{[29]}$. Moreover, the intensity of ultrasonic cavitation decreases with the ultrasonic frequency increases ${ }^{[19]}$. Accordingly, the coatings deposited under higher frequency ultrasonic agitation posses finer grains.

As shown in the SEM image (Fig. 3(a)), the asdeposited coating under silent condition exhibits a highly rough surface, which is quite different from those under ultrasonic agitation. In the case of silent electrodeposition, the coating surface is covered by large spherical clusters composing of random distributed dissimilar grains.

When applying $20 \mathrm{kHz}$ ultrasonic agitation, the morphology of the Ni-Co coatings changes to regularly branched acicular structure as shown in Fig. 3(b). The acicular crystallites have an average length of 3-4 $\mu \mathrm{m}$. By increasing the ultrasonic frequency to $55 \mathrm{kHz}$, the surface morphology as in Fig. 3(c) consists of pyramidal-shaped compact crystallites surrounded by tiny particles. The morphology of the NiCo coatings is composed of smaller spherical clusters when the ultrasonic frequency is increased further, as shown in Fig. 3(d) and (e). 

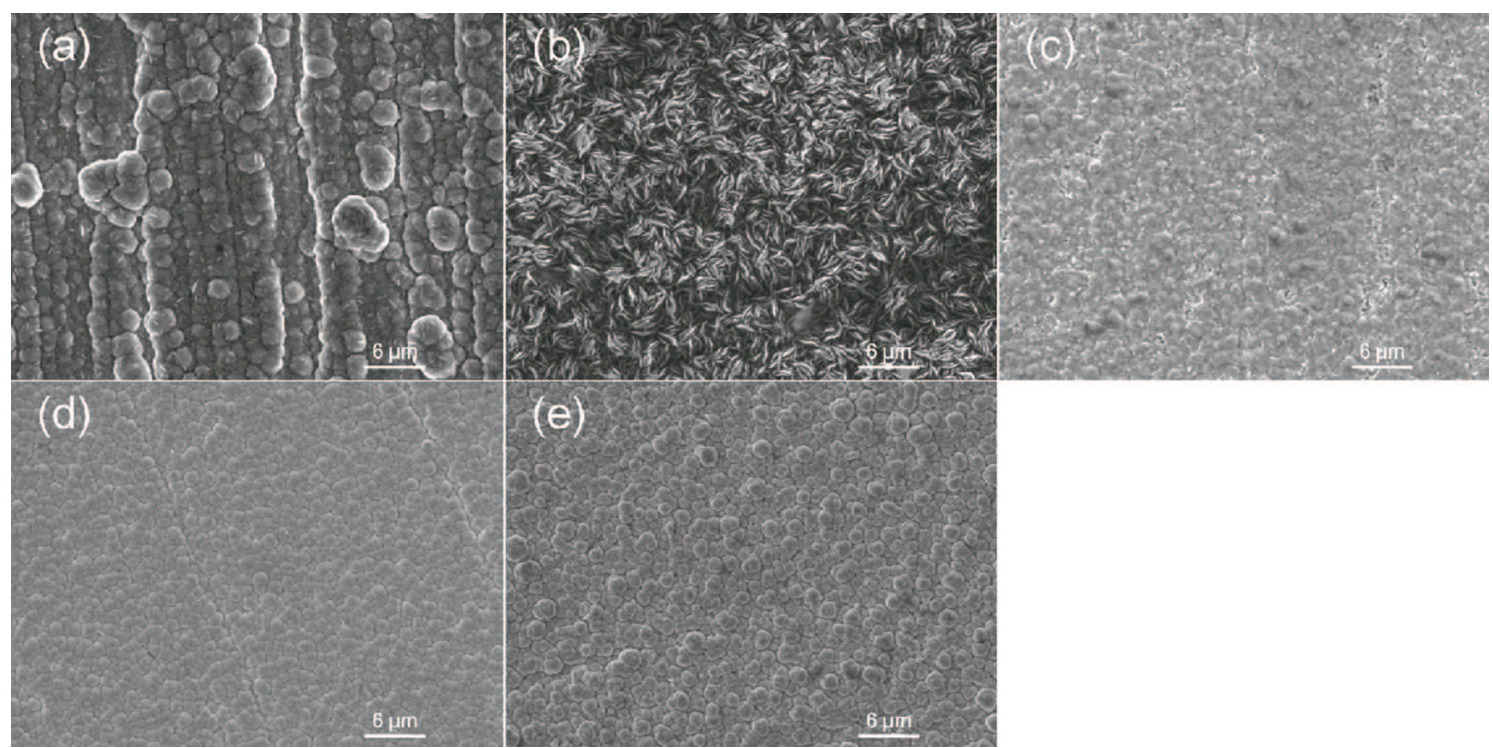

Fig. 3 Surface morphologies of the Ni-Co coatings deposited under different frequencies ultrasonic: (a) $0 \mathrm{kHz}$; (b) $20 \mathrm{kHz}$; (c) $55 \mathrm{kHz}$; (d) $90 \mathrm{kHz}$; (e) $120 \mathrm{kHz}$

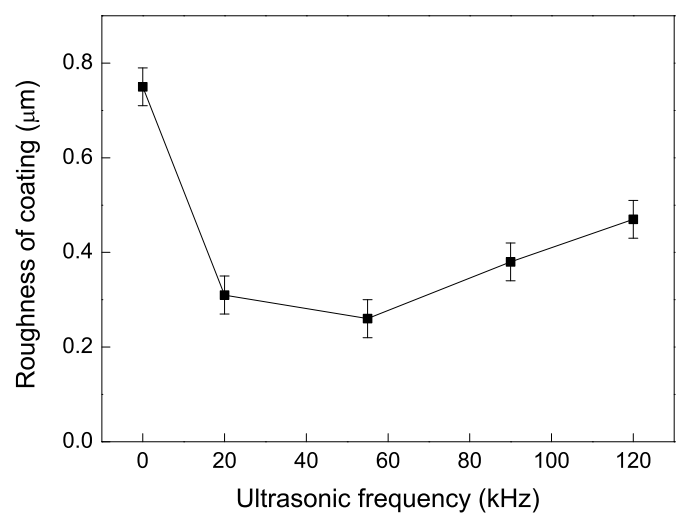

Fig. 4 The roughness of Ni-Co coatings deposited under different frequencies ultrasonic

\subsection{Evaluation of surface roughness}

The calculated surface roughness parameters $\left(R_{\mathrm{a}}\right.$, arithmetical mean deviation of the assessed profile) are shown in Fig. 4. The roughness of the Ni-Co coatings deposited under ultrasonic agitation is finer than that under silent condition. A possible reason is that the amount of crystal nuclei on the carbon steel surface increases under ultrasonic agitation. The grain size becomes smaller when more nuclei are formed, which makes more even coating surface, as shown in Fig. 3 and Table 3 .

\subsection{Evaluation of hardness}

The hardness results are shown in Fig. 5. All the $\mathrm{Ni}$-Co coatings are harder than the carbon steel substrate. The hardness of the coatings increases with the increase of the ultrasonic frequency up to $90 \mathrm{kHz}$, and then decreases slightly as the ultrasonic frequency larger than $90 \mathrm{kHz}$. Under $90 \mathrm{kHz}$ ultrasonic agita-

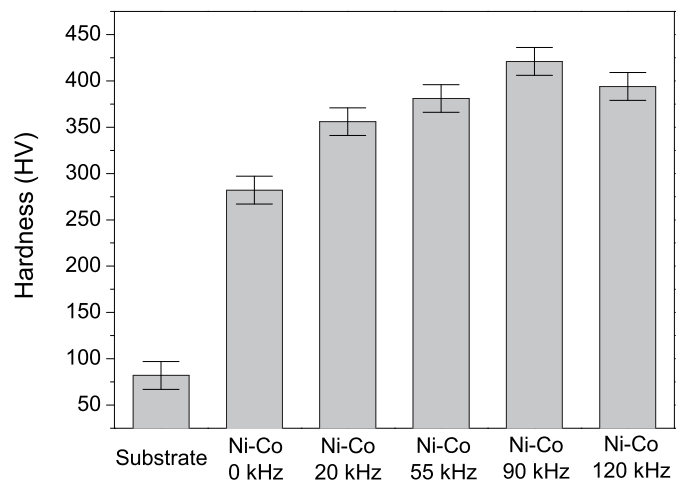

Fig. 5 The Vickers hardness of carbon steel substrate and Ni-Co coatings deposited under different frequencies ultrasonic

tion, the hardness reached a maximum value of about $420 \mathrm{HV}$. The initial hardness increase $(0-90 \mathrm{kHz})$ could be attributed to the grain size refinement effect, while the decrease of hardness at higher ultrasonic frequency $(120 \mathrm{kHz})$ could be explained with the inverse Hall-Petch relation ${ }^{[30]}$.

Fig. 6 shows the polarization plots of samples in 5 wt. $\% \mathrm{NaCl}$ solution at ambient temperature. Table 4 lists the data for corrosion potential $\left(E_{\text {corr }}\right)$, current density $\left(i_{\text {corr }}\right)$, anodic/cathodic Tafel slope $\left(b_{\mathrm{a}}\right.$ and $\left.b_{\mathrm{c}}\right)$ and polarization resistance $\left(R_{\mathrm{p}}\right)$ obtained from the polarization plots. It can be clearly observed from Fig. 6 that the carbon steel substrate reacts drastically with the $\mathrm{NaCl}$ solution, while all the Ni-Co coatings have more positive corrosion potential, much lower corrosion current density and higher polarization resistance. In contrast with the blank carbon steel substrate and the coating deposited under silent condition, all the coatings deposited under ultrasonic agitation have more positive corrosion potential, lower 
Table 4 Corrosion potential, current density, anodic/cathodic Tafel slope and polarization resistance obtained from the polarization plots as shown in Fig. 6

\begin{tabular}{cccccc}
\hline Sample & $E_{\text {corr }}(\mathrm{V})$ & $i_{\text {corr }}\left(\mu \mathrm{A} \cdot \mathrm{cm}^{-2}\right)$ & $b_{\mathrm{a}}\left(\mathrm{mV} \cdot \mathrm{dec}^{-1}\right)$ & $b_{\mathrm{c}}\left(\mathrm{mV} \cdot \mathrm{dec}^{-1}\right)$ & $R_{\mathrm{p}}\left(\Omega \cdot \mathrm{cm}^{-2}\right)$ \\
\hline Substrate & -0.747 & 16.217 & 122.726 & 99.386 & $1.471 \times 10^{3}$ \\
Ni-Co $(0 \mathrm{kHz})$ & -0.658 & 6.124 & 104.637 & 101.413 & $3.652 \times 10^{3}$ \\
Ni-Co $(20 \mathrm{kHz})$ & -0.556 & 1.235 & 87.441 & 105.519 & $1.682 \times 10^{4}$ \\
Ni-Co $(55 \mathrm{kHz})$ & -0.478 & 0.778 & 84.353 & 98.173 & $2.532 \times 10^{4}$ \\
Ni-Co $(90 \mathrm{kHz})$ & -0.601 & 2.116 & 90.212 & 104.452 & $9.931 \times 10^{3}$ \\
Ni-Co $(120 \mathrm{kHz})$ & -0.628 & 5.848 & 101.457 & 97.821 & $4.195 \times 10^{3}$ \\
\hline
\end{tabular}

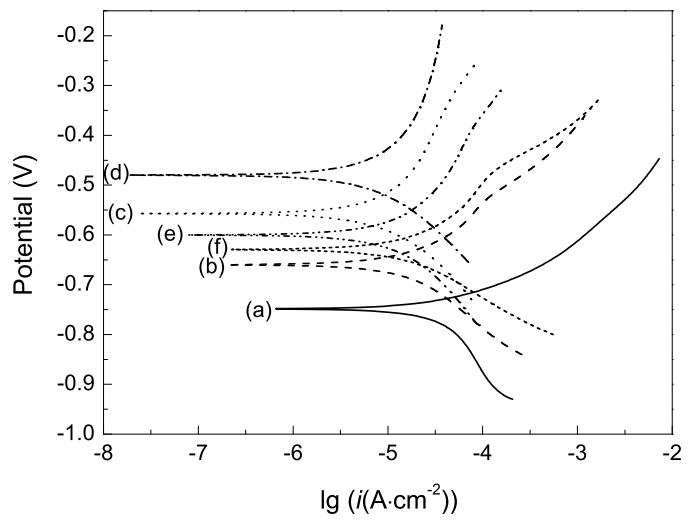

Fig. 6 Polarization plots of carbon steel substrate (a) and $\mathrm{Ni}$-Co coatings prepared under different ultrasonic frequency of $0 \mathrm{kHz}(\mathrm{b}), 20 \mathrm{kHz}$ (c), 55 $\mathrm{kHz}(\mathrm{d}), 90 \mathrm{kHz}(\mathrm{e})$ and $120 \mathrm{kHz}$ (f)

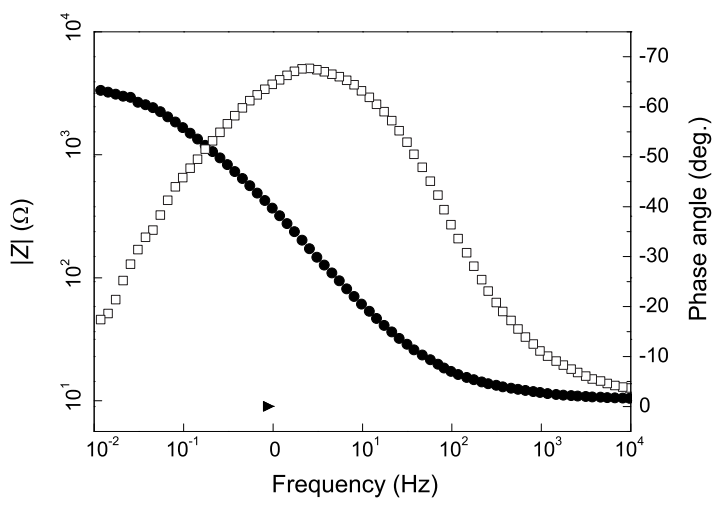

Fig. 7 Electrochemical impedance spectroscopy plots of carbon steel substrate

corrosion current density and higher polarization resistance. Among these coatings, the coating deposited under $55 \mathrm{kHz}$ ultrasonic agitation shows the highest polarization resistance $\left(R_{\mathrm{p}}=2.532 \times 10^{4} \Omega \cdot \mathrm{cm}^{-2}\right)$ and the lowest corrosion current density $\left(i_{\text {corr }}=0.778 \mu \mathrm{A} \cdot \mathrm{cm}^{-2}\right)$.

\subsection{Evaluation of corrosion performance}

Impedance plots (Bode plots) of the blank carbon steel substrate and the Ni-Co coatings are shown in Fig. 7 and Fig. 8, respectively. Bode plots of Frequency vs. phase angle exhibit a narrow peak, which indicates a single time constant for all the samples
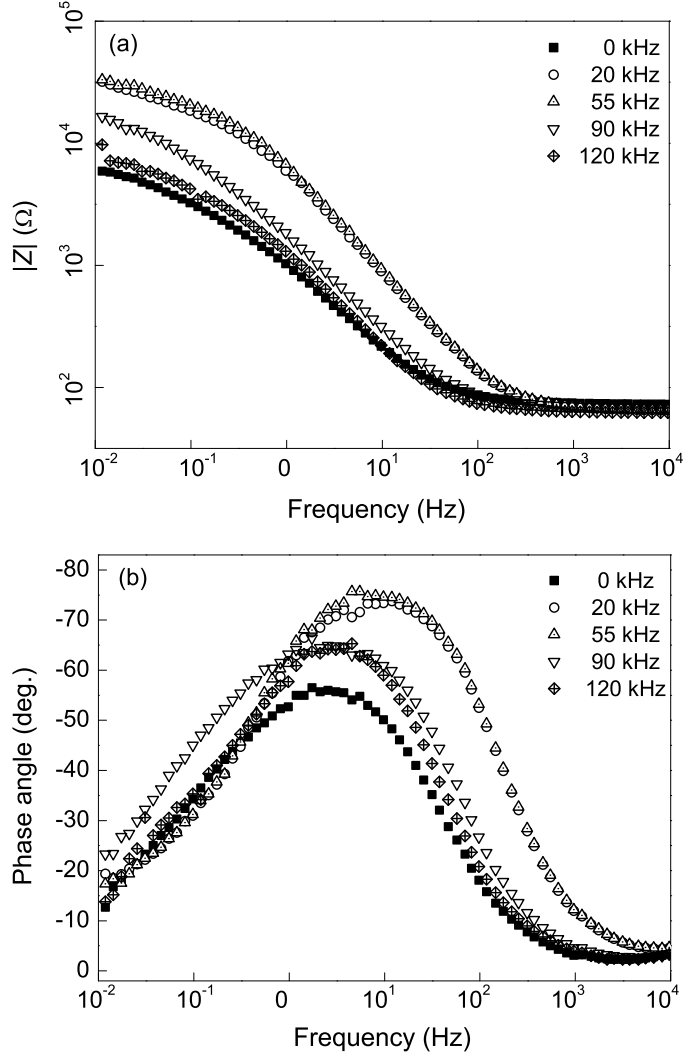

Fig. 8 Electrochemical impedance spectroscopy plots of $\mathrm{Ni}$-Co coatings prepared under different ultrasonic frequency: (a) $|Z|$ vs. frequency; (b) phase angle vs. frequency

studied (Fig. 7 and Fig. 8(b)). The single peaks observed correspond to the metal/electrolyte interface. This behavior can be modeled as a parallel combination of a double electric layer capacitance and a charge transfer resistance.

An equivalent circuit is shown in Fig. 9. Here $R_{\mathrm{s}}$ is the solution resistance and $Q_{\mathrm{dl}}$ stands for the possibility of a non-ideal capacitance of a double electric layer (CPE, constant phase element) with various $n_{\mathrm{dl}}$. The CPE represents a frequency dispersion of time constants originated from the local inhomogeneity or roughness or porosity of the surface ${ }^{[5]} \cdot R_{\mathrm{ct}}$ is the charge transfer resistance of electrode reaction.

The calculated parameters are presented in Table 5 . The $R_{\text {ct }}$ values increase in the order: carbon steel substrate, Ni-Co $(0 \mathrm{kHz})$, Ni-Co $(120 \mathrm{kHz})$, NiCo $(90 \mathrm{kHz})$, Ni-Co $(20 \mathrm{kHz})$ and $\mathrm{Ni}-\mathrm{Co}(55 \mathrm{kHz})$. The largest $R_{\text {ct }}$ value is at $55 \mathrm{kHz}$ for Ni-Co coat- 
Table 5 Impedance parameters for carbon steel substrate and Ni-Co coatings

\begin{tabular}{ccccc}
\hline Sample & $R_{\mathrm{s}}(\Omega)$ & $Q_{\mathrm{dl}}\left(\mu \mathrm{F} \cdot \mathrm{cm}^{-2}\right)$ & $n_{\mathrm{dl}}$ & $R_{\mathrm{ct}}\left(\Omega \cdot \mathrm{cm}^{-2}\right)$ \\
Substrate & 6.547 & 38.957 & 0.89 & $4.124 \times 10^{3}$ \\
\hline Ni-Co $(0 \mathrm{kHz})$ & 5.904 & 66.789 & 0.79 & $7.686 \times 10^{3}$ \\
Ni-Co $(20 \mathrm{kHz})$ & 8.326 & 45.568 & 0.86 & $3.488 \times 10^{4}$ \\
Ni-Co $(55 \mathrm{kHz})$ & 6.896 & 37.456 & 0.87 & $4.321 \times 10^{4}$ \\
Ni-Co $(90 \mathrm{kHz})$ & 4.987 & 51.321 & 0.82 & $1.723 \times 10^{4}$ \\
Ni-Co $(120 \mathrm{kHz})$ & 7.132 & 43.905 & 0.81 & $8.926 \times 10^{3}$ \\
\hline
\end{tabular}

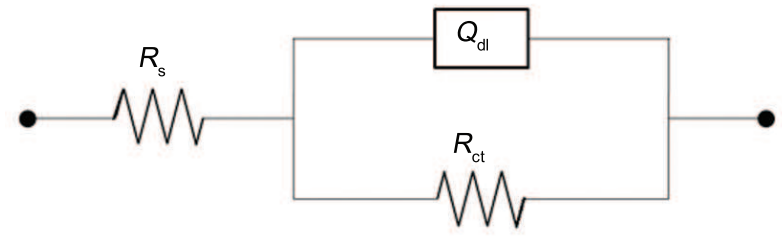

Fig. 9 Equivalent circuit for fitting the electrochemical impedance spectroscopy

ing indicates that the active area available for corrosive attack is less or alternatively the corrosion resistance is higher compared with others. The $R_{\mathrm{p}}$ values obtained from polarization studies has also exhibited similar pattern thereby affirming the above results.

From Table 5, it can be found that the Ni-Co $(55 \mathrm{kHz})$ sample has the smallest $Q_{\mathrm{dl}}$ value, which implies that applying $55 \mathrm{kHz}$ ultrasonic agitation can improve the surface morphology of the coating and decrease the surface defects. Further, $n_{\mathrm{dl}}$ values for carbon steel substrate, Ni-Co $(20 \mathrm{kHz})$ and $\mathrm{Ni}-\mathrm{Co}$ $(55 \mathrm{kHz})$ lie in a narrow range of $0.86-0.89$ demonstrate the low capacitive behavior of these samples. Whereas, the $n_{\mathrm{dl}}$ values for Ni-Co $(0 \mathrm{kHz})$, Ni-Co $(90$ $\mathrm{kHz})$ and $\mathrm{Ni}-\mathrm{Co}(120 \mathrm{kHz})$ are less than 0.82 , which suggests the much lower capacitive nature of these coatings. Bode plots (Fig. 7 and Fig. 8(b)) show that the phase angles of $\mathrm{Ni}-\mathrm{Co}(0 \mathrm{kHz}), \mathrm{Ni}-\mathrm{Co}(90 \mathrm{kHz})$ and $\mathrm{Ni}-\mathrm{Co}(120 \mathrm{kHz})$ are distributed between $50^{\circ}$ and $65^{\circ}$. As for carbon steel substrate, Ni-Co $(20 \mathrm{kHz})$ and Ni-Co $(55 \mathrm{kHz})$, the phase angles are within the range of $70^{\circ}-75^{\circ}$, which also reveals better capacitive behaviors.

\section{Conclusions}

The results of the current study can be summarized as follows:

(1) The Ni-Co coatings produced by eletrodeposition method under ultrasonic agitation were uniform, compact and composed of fine grains.

(2)The ultrasonic frequency had a significant impact on the composition and grain size of the $\mathrm{Ni}-\mathrm{Co}$ coatings. Both the $\mathrm{Ni}$ content and the grain size of $\mathrm{Ni}-$ Co coatings decreased with the ultrasonic frequency from $20 \mathrm{kHz}$ to $120 \mathrm{kHz}$.

(3) When electrodeposition was conducted under a proper ultrasonic frequency, all the properties of
Ni-Co coatings could be improved. The hardness reached a maximum value of about $420 \mathrm{HV}$ at $90 \mathrm{kHz}$. Whereas, the coating produced at $55 \mathrm{kHz}$ exhibited the strongest corrosion resistance.

\section{Acknowledgements}

This work was financially supported by the National Nature Science Fund of China (No. 51204115).

\section{REFERENCES}

[1] T. Osaka, M. Takai, K. Ohashi, M. Saito and K. Yamada, Nature 392 (1998) 796.

[2] T. Osaka, Electrochim. Acta. 44 (1999) 3855.

[3] K.Y. Sasaky and J.B. Talbot, J. Eletrochem. Soc. 147 (2000) 189.

[4] D. Golodnitsky, N.V. Gudin and G.A. Volyanuk, J. Eletrochem. Soc. 147 (2000) 4156.

[5] M. Srivastava, V.E. Selvi, V.K.W. Grips and K.S. Rajam, Surf. Coat. Technol. 201 (2006) 3051

[6] B. Tury, M.L. Varsányi and S. Roy, Appl. Surf. Sci. 253 (2007) 3103.

[7] L.M. Chang, H.F. Guo and M.Z. An, Mater. Lett. 62 (2008) 3313.

[8] C. Lupi, A. Dell'Era, M. Pasquali and P. Imperatori, Surf. Coat. Technol. 205 (2011) 5394.

[9] L. Tian, J. Xu and S. Xiao, Vacuum 86 (2011) 27.

[10] C.D. Gu, J.S. Lian and Z.H. Jiang, Adv. Eng. Mater. 8 (2006) 252.

[11] H.Y. Zhang and M.Z. An, J. Alloys Compd. 459 (2008) 548.

[12] R. Kas, F.S. Ertas and Ö. Birer, Appl. Surf. Sci. 259 (2012) 501.

[13] M. Kim, F. Sun, J. Lee, Y.K. Hyum and D. Lee, Surf. Coat. Technol. 205 (2010) 2362.

[14] M. Sheng, C. Wang, Q. Zhong, Y. Wei and Y. Wang, Ultrason. Sonochem. 17 (2010) 21.

[15] E.G. Lecina, I.G. Urrutia, J.A. Diez, J. Morgiel and P. Indyka, Surf. Coat. Technol. 206 (2012) 2998.

[16] F. Xia, M. Wu, F. Wang, Z. Jia and A. Wang, Curr. Appl. Phys. 9 (2009) 44.

[17] T. Ohsaka, M. Isaka, K. Hirano and T. Ohishi, Ultrason. Sonochem. 15 (2008) 283.

[18] B.G. Pollet, J.Y. Hihn and T.J. Mason, Electrochim. Acta. 53 (2008) 4248.

[19] G.O.H. Whillock and B.F. Harvey, Ultrason. Sonochem. 4 (1997) 33.

[20] Y. Niu, J. Wei, Y.Yang, J. Hu and Z. Yu, Surf. Coat. Technol. 210 (2012) 21. 
[21] R. Oriňáková, A. Oriňák, G. Vering, I. Talian, R. M. Smith and H. F. Arlinghaus, Thin Solid Films 516 (2008) 3045.

[22] L. Wang, Y. Gao, Q. Xue, H. Liu and T. Xu, Appl. Surf. Sci. 242 (2005) 326.

[23] A. Bai and C. Hu, Electrochem. Acta. 47 (2002) 3447.

[24] C.K. Chung and W.T. Chang, Thin Solid Films 517 (2009) 4800.

[25] B. Tury, M.L. Varsányi and S. Roy, Surf. Coat. Technol. 200 (2006) 6713.
[26] R.S. Hagan and L.A. Coury, Anal. Chem. 66 (1994) 399.

[27] E.L. Cooper and L.A. Coury, J. Eletrochem. Soc. 145 (1998) 1994.

[28] R.G. Compton, J.C. Eklund, S.D. Page, G.H.W Sanders and J. Booth, J. Phys. Chem. 98 (1994) 12410.

[29] Y. Li, H. Jiang, W. Huang and H. Tian, Appl. Surf. Sci. 254 (2008) 6865.

[30] Y. Li, H. Jiang, D. Wang and H. Ge, Surf. Coat. Technol. 202 (2008) 4952. 